University of Wollongong

Research Online

Australian Institute for Innovative Materials -

Papers

Australian Institute for Innovative Materials

$1-1-2013$

Band structure, magnetic, and transport properties of two dimensional compounds $\mathrm{Sr} 2-\mathrm{xGdxCoO4}$

Q W Yao

University of Wollongong, qy75@uow.edu.au

Xiaolin Wang

University of Wollongong, xiaolin@uow.edu.au

H Kimura

National Institute For Materials Science

S X. Dou

University of Wollongong, shi@uow.edu.au

Konstantin Konstantinov

University of Wollongong, konstan@uow.edu.au

See next page for additional authors

Follow this and additional works at: https://ro.uow.edu.au/aiimpapers

Part of the Engineering Commons, and the Physical Sciences and Mathematics Commons

Research Online is the open access institutional repository for the University of Wollongong. For further information contact the UOW Library: research-pubs@uow.edu.au 


\title{
Band structure, magnetic, and transport properties of two dimensional compounds Sr2-xGdxCoO4
}

\begin{abstract}
The layered perovskite compound $\mathrm{Sr} 2-\mathrm{xGdxCoO} 4$ has not yet been subjected to detailed study so far. In this report, structures, transport, magnetic properties, and first principle calculations will be reported for the two dimensional compounds $\mathrm{Sr} 2-x \mathrm{xdxCoO} 4$ (x 0.5, 0.75, 1, 1.25). Rietveld refinement revealed that these compounds are crystallized in $\mathrm{K} 2 \mathrm{NiF}$ 4-type structures with space group $14 / \mathrm{mmm}$. It was found that the lattice parameter $\mathrm{c}$ decreases as $\mathrm{x}$ increases. Through the Curies Weiss fitting of the temperature dependent magnetization, it was found that the $\mathrm{Sr} 1.25 \mathrm{Gd} 0.75 \mathrm{CoO} 4$ sample exhibits a weak ferromagnetic to paramagnetic transition at about $62 \mathrm{~K}$, with a Curie constant of $0.113 \mathrm{emu} \mathrm{K} / \mathrm{mol}$. Band structure calculations indicated that electrons of these compounds are spin polarized at the Fermi level. The 2-D Variable Range Hopping model fitting indicated that the two dimensional variable range hopping mechanism could be used to account for the conducting mechanism for these samples. 2013 American Institute of Physics.
\end{abstract}

\section{Keywords}

compounds, dimensional, two, properties, transport, sr2, magnetic, xgdxcoo4, structure, band

\section{Disciplines}

Engineering | Physical Sciences and Mathematics

\section{Publication Details}

Yao, Q., Wang, X., Kimura, H., Dou, S. X., Konstantinov, K., Cheng, Z. X., Hong, F., Zhao, H., Qiu, H. \& Ozawa, $\mathrm{K}$. (2013). Band structure, magnetic, and transport properties of two dimensional compounds Sr2-xGdxCo04. Journal of Applied Physics, 113 (17), 17B522-1-17B522-3.

\section{Authors}

Q W Yao, Xiaolin Wang, H Kimura, S X. Dou, Konstantin Konstantinov, Z X. Cheng, F Hong, H Zhao, H Qiu, and Kiyoshi Ozawa 
AIP Appinied Physics

\section{Band structure, magnetic, and transport properties of two dimensional compounds Sr2-xGdxCoO4}

Q. W. Yao, X. L. Wang, H. Kimura, S. X. Dou, K. Konstantinov et al.

Citation: J. Appl. Phys. 113, 17B522 (2013); doi: 10.1063/1.4799780

View online: http://dx.doi.org/10.1063/1.4799780

View Table of Contents: http://jap.aip.org/resource/1/JAPIAU/v113/i17

Published by the American Institute of Physics.

\section{Additional information on J. Appl. Phys.}

Journal Homepage: http://jap.aip.org/

Journal Information: http://jap.aip.org/about/about_the_journal

Top downloads: http://jap.aip.org/features/most_downloaded

Information for Authors: http://jap.aip.org/authors

\section{ADVERTISEMENT}

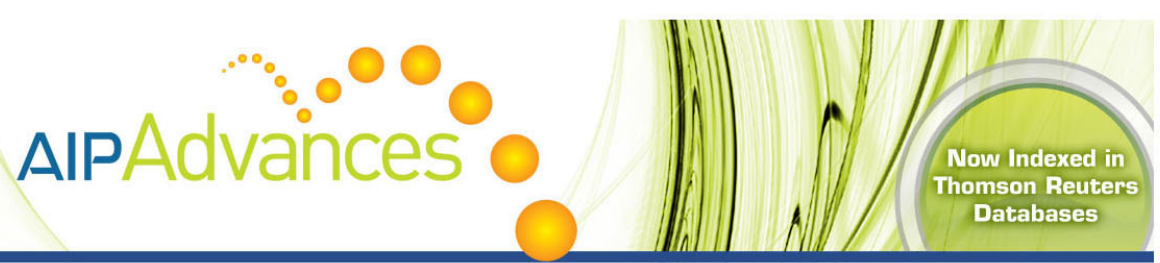

\section{Explore AIP's open access journal: •Rapid publication \\ - Article-level metrics \\ - Post-publication rating and commenting}




\title{
Band structure, magnetic, and transport properties of two dimensional compounds $\mathrm{Sr}_{2-\mathrm{x}} \mathrm{Gd}_{\mathrm{x}} \mathrm{CoO}_{4}$
}

\author{
Q. W. Yao, ${ }^{1, a)}$ X. L. Wang, ${ }^{1}$ H. Kimura,${ }^{2}$ S. X. Dou, ${ }^{1}$ K. Konstantinov, ${ }^{1}$ Z. X. Cheng, ${ }^{1}$ \\ F. Hong, ${ }^{1}$ H. Y. Zhao, ${ }^{2} \mathrm{H}$. Qiu, ${ }^{2}$ and K. Ozawa ${ }^{2}$ \\ ${ }^{1}$ Institute for Superconducting and Electronic Materials, University of Wollongong, Wollongong 2500, NSW, \\ Australia \\ ${ }^{2}$ Multifunctional Materials Group, Optical and Electronic Materials Unit, National Institute for Materials \\ Science, Tsukuba, Ibaraki 305-0047, Japan
}

(Presented 18 January 2013; received 5 November 2012; accepted 15 January 2013; published online 9 April 2013)

\begin{abstract}
The layered perovskite compound $\mathrm{Sr}_{2-\mathrm{x}} \mathrm{Gd}_{\mathrm{x}} \mathrm{CoO}_{4}$ has not yet been subjected to detailed study so far. In this report, structures, transport, magnetic properties, and first principle calculations will be reported for the two dimensional compounds $\mathrm{Sr}_{2-x} \mathrm{Gd}_{\mathrm{x}} \mathrm{CoO} 4(x=0.5,0.75,1,1.25)$. Rietveld refinement revealed that these compounds are crystallized in $\mathrm{K}_{2} \mathrm{NiF}_{4}$-type structures with space group $\mathrm{I} 4 / \mathrm{mmm}$. It was found that the lattice parameter $c$ decreases as $x$ increases. Through the Curies Weiss fitting of the temperature dependent magnetization, it was found that the $\mathrm{Sr}_{1.25} \mathrm{Gd}_{0.75} \mathrm{CoO}_{4}$ sample exhibits a weak ferromagnetic to paramagnetic transition at about $62 \mathrm{~K}$, with a Curie constant of $0.113 \mathrm{emu} \mathrm{K} / \mathrm{mol}$. Band structure calculations indicated that electrons of these compounds are spin polarized at the Fermi level. The 2-D Variable Range Hopping model fitting indicated that the two dimensional variable range hopping mechanism could be used to account for the conducting mechanism for these samples. (C) 2013 American Institute of Physics. [http://dx.doi.org/10.1063/1.4799780]
\end{abstract}

\section{INTRODUCTION}

Very recently, metallic ferromagnetism with a Curie temperature $\mathrm{Tc}$ of $250 \mathrm{~K}$ has been discovered in the $\mathrm{K}_{2} \mathrm{NiF}_{4}$ type two-dimensional layered perovskite $\mathrm{Sr}_{2} \mathrm{CoO}_{4}$ ceramic produced by a high pressure and high temperature technique, ${ }^{1}$ with large magnetic anisotropy, and quasi-two-dimensional electrical transport properties. In fact two dimensional compounds with the $\mathrm{K}_{2} \mathrm{NiF}_{4}$-type structure has been a great interest for materials researchers in recent years, ${ }^{2-10}$ due to their interesting properties such as superconductivity, ionic and electronic conductivity, magnetoresistance, dielectric properties, catalysis, spin/charge stripes in nickelates, manganites, etc. The non-magnetic yttrium doping of $\mathrm{Sr}_{2} \mathrm{CoO}_{4}$ polycrystalline samples fabricated under high pressure was found to change the system from ferromagnetic metal to antiferromagnetic semiconductor. ${ }^{1}$ It would be interesting to see the changes in physical properties such as the transport properties, Curie temperatures, and the electronic structures of the $\mathrm{Sr}_{2} \mathrm{CoO}_{4}$ by doping it with the $\mathrm{Gd}$ which has large magnetic moments.

\section{EXPERIMENT AND CALCULATIONS}

Polycrystalline samples $\mathrm{Sr}_{2-x} \mathrm{Gd}_{\mathrm{x}} \mathrm{CoO}_{4}(x=0.5,0.75,1$, 1.25) were synthesized by conventional solid-state reaction method. Fine and pure (99.9\%) powders of $\mathrm{Gd}_{2} \mathrm{O}_{3}, \mathrm{SrCO}_{3}$, and $\mathrm{Co}_{3} \mathrm{O}_{4}$ were mixed in the appropriate stoichiometries, pelletized, and sintered in air at $1000^{\circ} \mathrm{C}$ for $12 \mathrm{~h}$ with several intermediate grindings. The resultant phases and structures

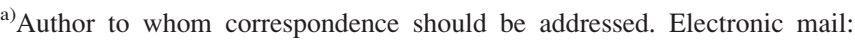
wen@uow.edu.au.
}

were studied by the powder x-ray diffraction (XRD). Structure refinements were carried out by the Rietveld method using the RIETICA program. ${ }^{11}$ Magnetic and electrical transport properties were investigated using a commercial Quantum Design magnetic property measurement system (MPMS) and physical property measurement system (PPMS) system in magnetic fields up to $8 \mathrm{~T}$. First principles calculations were performed to the compounds using the WIEN $2 \mathrm{~K}$ package. $^{12}$

\section{RESULTS AND DISCUSSIONS}

The XRD measurements of the $\mathrm{Sr}_{2-\mathrm{x}} \mathrm{Gd}_{\mathrm{x}} \mathrm{CoO}_{4}$ samples showed that the diffraction peaks of all the four samples fit well with the XRD profile of the $\mathrm{Sr}_{2} \mathrm{CoO}_{4}$ single phase. A small unknown phase diffraction peak was found in the range of $32.5^{\circ}$ to $33^{\circ}$ in the XRD patterns for the samples where $\mathrm{x}>=0.75$. Fig. 1 shows the Rietveld refinement result of the $\mathrm{Sr}_{1.25} \mathrm{Gd}_{0.75} \mathrm{CoO}_{4}$ sample. The lattice parameters $a$ and $c$ were obtained through the refinement results. As shown in the inset of Fig. 1, the lattice parameter $a$ was found to be not sensitive to the doping level of $\mathrm{Gd}$ and remains around $3.75 \AA$ for all samples, while the lattice parameter $c$ decreases as the Gd doping level $x$ increases. This is in agreement with the fact that the Pauling ionic radius of $\mathrm{Gd}^{3+}$ (radius $1.08 \AA$ ) is smaller than the ionic radius of $\mathrm{Sr}^{2+}$ (radius $1.32 \AA) .{ }^{13}$

The temperature dependence of the electrical resistivity in a temperature range of $25 \mathrm{~K}$ to $350 \mathrm{~K}$ for the samples with $\mathrm{x}=0.75,1$, and 1.25 is shown in Fig. 2(a). The resistivity of all these samples in temperatures below $25 \mathrm{~K}$ became too large that they were beyond the measurable range of the PPMS. All three samples exhibited semiconductor-like 


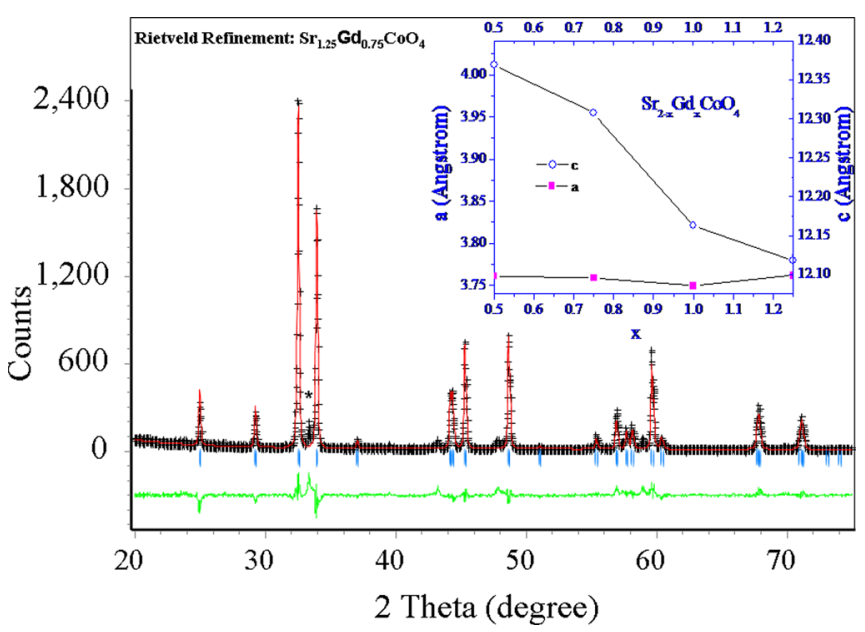

FIG. 1. Rietveld refinement for $\mathrm{Sr}_{1.25} \mathrm{Gd}_{0.75} \mathrm{CoO}_{4}$ showing the observed (crosses), calculated (solid line), and difference (bottom line) profiles at $300 \mathrm{~K}$ (refinement factors $\mathrm{Rp}=14.3 \%, \mathrm{Rb}=6.2 \%$ ). The star marks the small unknown phase peak in the range of $32.5^{\circ}$ and $33^{\circ}$. Inset shows the Lattice parameters $a$ and $c$ vs $x$ for $\mathrm{Sr}_{2-\mathrm{x}} \mathrm{Gd}_{\mathrm{x}} \mathrm{CoO}_{4}$.

behavior over the measurable range. It can also be seen that the Gd doping increases the resistivity of the compound. It should be noted that, through our conventional method of doping by $\mathrm{Gd}$, the ceramic compound $\mathrm{Sr}_{2} \mathrm{CoO}_{4}$ changes from a metal to semiconductors, while Wang has reported that smaller amount of doping by $\mathrm{Gd}$ to this ceramic compound (e.g., $\mathrm{Sr}_{1.7} \mathrm{Gd}_{0.3} \mathrm{CoO}_{4}$ ) by high pressure method did not change much of the compound's transport property. ${ }^{14}$ The $\log$ of the resistivity $(\rho) \operatorname{vs} \exp (1 / \mathrm{T})^{1 / 3}$ for these samples is shown in Fig. 2(b). It can be seen that the data for these samples basically fit well with the variable range hopping (VRH) model in their measurable ranges. This suggests that the 2D VRH mechanism could be used to account for the conducting mechanism for these samples.

Fig. 3 shows the temperature dependence for fieldcooled and zero-field-cooled measurements from $5 \mathrm{~K}$ to $300 \mathrm{~K}$ of the magnetization of the $\mathrm{Sr}_{2-\mathrm{x}} \mathrm{Gd}_{\mathrm{x}} \mathrm{CoO}_{4}$ samples with $\mathrm{x}=0.75$ and 1 , measured in a magnetic field of $0.2 \mathrm{~T}$. Inset shows the Curie Weiss fitting for both measurements. Both samples appear to be in the paramagnetic state over the whole measured temperature range from the magnetization (MT) curves. The $\mathrm{SrGdCoO}_{4}$ sample shows typical features

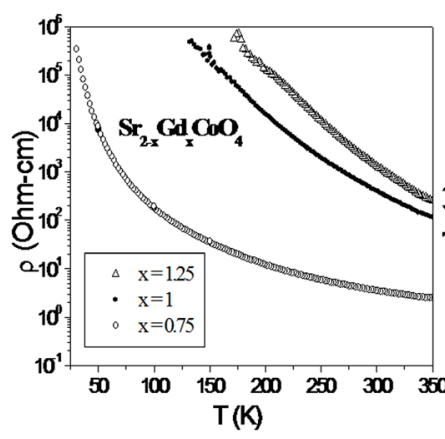

(a)

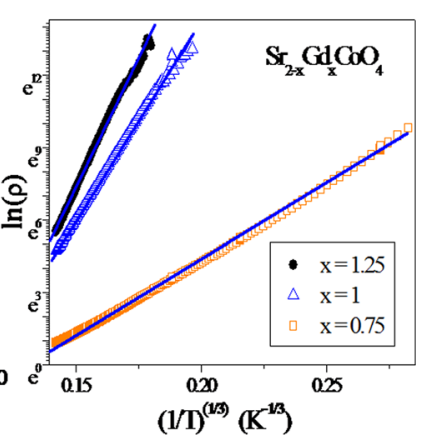

(b)
FIG. 2. (a) Resistance vs temperature for $\mathrm{Sr}_{2-\mathrm{x}} \mathrm{Gd}_{\mathrm{x}} \mathrm{CoO}_{4}(\mathrm{x}=0.75,1,1.25)$. (b) $\ln (\rho) \operatorname{vs} \exp (1 / \mathrm{T})^{1 / 3}$ for $\mathrm{Sr}_{2-\mathrm{xG}} \mathrm{Gd}_{\mathrm{x}} \mathrm{CoO}_{4}(\mathrm{x}=0.75,1,1.25)$. Straight lines are linear fittings to the $2 \mathrm{D}$ VRH model.

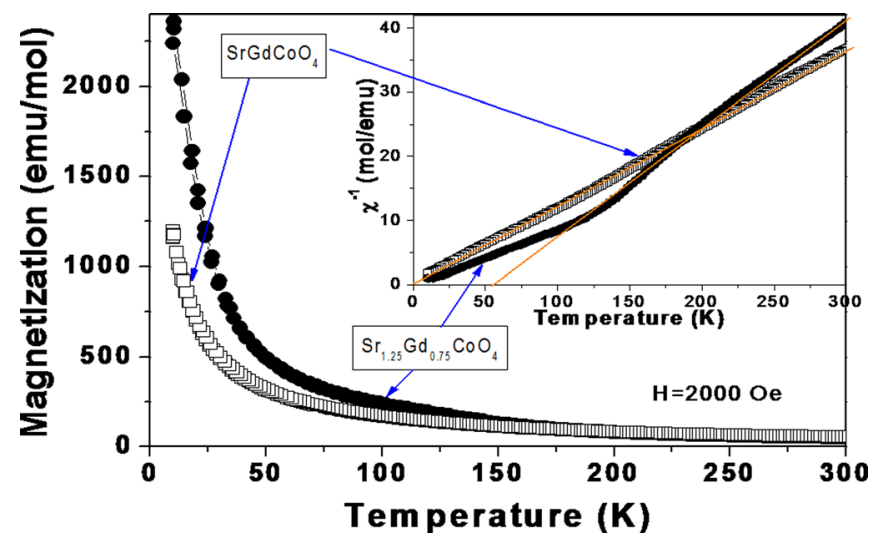

FIG. 3. Temperature dependence of the magnetization of the $\mathrm{Sr}_{2-\mathrm{x}} \mathrm{Gd}_{\mathrm{x}} \mathrm{CoO}_{4}$ samples with $\mathrm{x}=0.75,1$. Inset shows the Curie Weiss fitting of the samples.

of a paramagnet. Furthermore, as can be seen in the inset in Fig. 3, a slight concavity in the temperature dependence of the inverse susceptibility is observed at around $120 \mathrm{~K}$ for the $\mathrm{Sr}_{1.25} \mathrm{Gd}_{0.75} \mathrm{CoO}_{4}$ sample, indicating a short range ferromagnetic or antiferromagnetic state change at this point for this compound. Magnetization hysteresis measurements for both samples measured at $10 \mathrm{~K}$ (not shown here) confirm a week ferromagnetic interaction in the low field range for this sample. From the Curies Weiss fitting, it was found that the $\mathrm{Sr}_{1.25} \mathrm{Gd}_{0.75} \mathrm{CoO}_{4}$ sample exhibited a weak ferromagnetic to paramagnetic transition at about $62 \mathrm{~K}$, with a Curie Constant of $0.113 \mathrm{emu} \mathrm{K} / \mathrm{mol}$.

It should be noted that the resistivity monotonically increases with decreasing temperature from 350 to $5 \mathrm{~K}$ (Fig. 2(a)), and no anomaly occurs at magnetic transition temperature observed. All samples show a semiconducting character. This reveals that the variation in the resistivity with temperature for these compounds is not dominated by spin-dependent scattering of carriers, but by carrier concentration. $^{15}$

The first-principal calculations performed for the $\mathrm{SrGdCoO}_{4}$ compound in ground state indicated that the spin polarization is high in this compound. Lattice parameters and atomic positions obtained from the Rietveld refinements for this sample were used as the starting unit cell parameters for the calculations. Geometry optimization was employed to find the optimal parameters for the final calculation. An eight atom supercell was used for the calculation; a $10 \times 10 \times 3 k$ mesh was used for the Brillouin sampling. It should be noted that the supercell choice of the calculation does not affect the resulting DOS in this case (as it was a $1 \times 1 \times 1$ supercell), and all DOS units are given as per formula unit. Fig. 4(a) shows the total DOS of $\mathrm{SrGdCoO}_{4}$ (with the Fermi energy set at zero). The spin down DOS is approximately three times the spin up DOS value at the Fermi level. Our result is in good agreement with the results of the electronic structure from Wang et al. which was obtained by a different calculation package. ${ }^{14}$ Fig. 4(b) shows the total DOS (thick yellow curves) vs the Gd's DOS (thin blue curve) of the compound. It can be seen that the $\mathrm{Gd}$ atom does not contribute to any electronic density at the Fermi level. Fig. 4(c) shows the total DOS (thick yellow curves) vs the Co2's DOS (thin blue curve). It can be seen that the main DOS at the Fermi level 

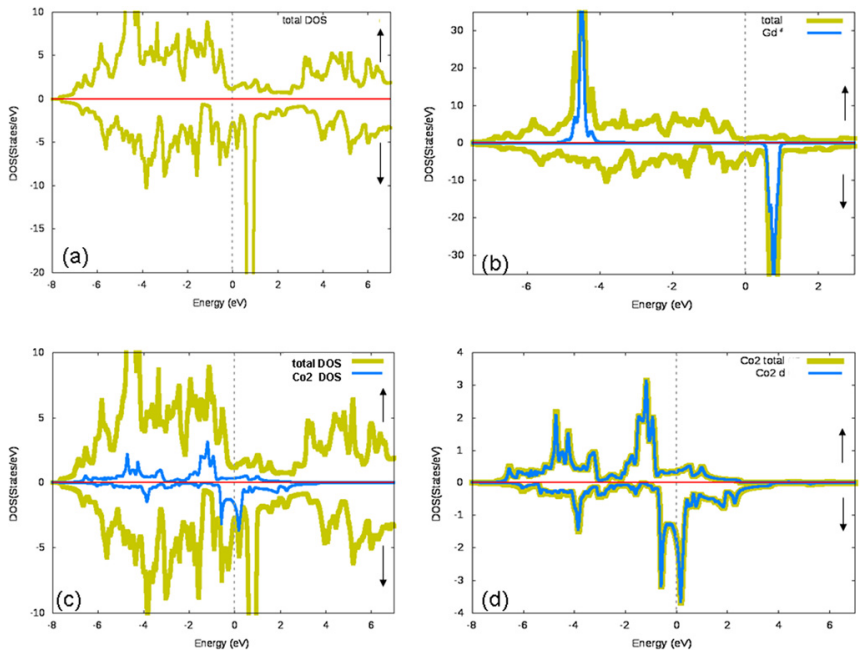

FIG. 4. Calculated DOS of $\mathrm{SrGdCoO}_{4}$. (a) The total DOS of $\mathrm{SrGdCoO}_{4}$. (b) The total DOS of $\mathrm{SrGdCoO}_{4}$ (yellow and thick curves) and the Gd's DOS (blue and thin curves). (c) The total DOS of $\mathrm{SrGdCoO}_{4}$ (yellow and thick curves) and the Co2's DOS (blue and thin curves). (d) Co2's total DOS (yellow and thick curves) and the contribution from Co2's $3 \mathrm{~d}$ electrons (blue and thin curves).

mainly comes from the contribution of the Co atoms. It should be noted that the spin polarization of the compound comes from the Co atoms, since basically both of the two $\mathrm{O}$ atoms and the Gd atom in the unit cell do not contribute to the DOS of the compound at the Fermi level. Fig. 4(d) shows the Co2's total DOS (thick yellow curves) vs the DOS of the Co2's 3d electrons (thin blue curve). It can be seen that the two curves are overlapping over the calculated range, indicating that the Cobalt's $3 d$ electrons are the only contributors to Cobalt atom's DOS.

In conclusion, $\mathrm{Gd}$ doping by the conventional solid state reaction method changes the $\mathrm{Sr}_{2} \mathrm{CoO}_{4}$ ceramic compound from a ferromagnetic metal to paramagnets, the lattice parameter $c$ decreases as the $\mathrm{Gd}$ doping level increases. The
$\mathrm{Sr}_{1.25} \mathrm{Gd}_{0.75} \mathrm{CoO}_{4}$ sample exhibited a weak ferromagnetic to paramagnetic transition at about 62 . First principle calculations indicated that these compounds show high spin polarization (which contributed mainly by the Cobalt's $3 \mathrm{~d}$ orbital electrons) at the Fermi level.

\section{ACKNOWLEDGMENTS}

This work was supported by the Australian Research Council's through the project of DP0987190 and DP1094073, and the Japanese government's JSPS Fellowship program, the JST ALCA as well as the MEXT GRENE projects.

${ }^{1}$ X. L. Wang and E. Takayama-Muromachi, Phys. Rev. B 72, 064401 (2005).

${ }^{2}$ J. Matsuno, Y. Okimoto, Z. Fang, X. Z. Xu, Y. Matsui, N. Nagaosa, M. Kawasaki, and Y. Tokura, Phys. Rev. Lett. 93, 167202 (2004).

${ }^{3}$ Q. W. Yao, X. L. Wang, Z. X. Cheng, G. Peleckis, S. X. Dou, and R. Nigam, J. Appl. Phys. 101, 09N515 (2007).

${ }^{4}$ Y. Moritomo, K. Higashi, K. Matsuda, and A. Nakamura, Phys. Rev. B 55, R14725 (1997).

${ }^{5}$ Y. Shimada, S. Miyasaka, R. Kumai, and Y. Tokura, Phys. Rev. B 73, 134424 (2006).

${ }^{6}$ M. Ziese, Rep. Prog. Phys. 65, 143 (2002).

${ }^{7}$ K.-I. Kobayashi, T. Kimura, H. Sawada, K. Terakura, and Y. Tokura, Nature (London) 395, 677 (1998).

${ }^{8}$ Y. Y. Liu, X. M. Chen, X. Q. Liu, and L. Li, J. Electroceram. 21, 706-710 (2008).

${ }^{9}$ R. Ang, Y. P. Sun, X. Luo, C. Y. Hao, X. B. Zhu, and W. H. Song, J. Appl. Phys. 104, 023914 (2008).

${ }^{10}$ Q. W. Yao, X. L. Wang, and S. X. Dou, J. Appl. Phys. 103, $07 B 904$ (2008).

${ }^{11}$ B. A. Hunter, Comm. Powder Diffr. Newsl. 20, 21 (1998).

${ }^{12}$ P. Blaha, K. Schwarz, G. K. H. Madsen, D. Kvanicka, and J. Luitz, WIEN $2 K$, An Augmented plane wave + Local Orbital Program for Calculating Crystal Properties, Karlheinz Schwarz, Techn. Universitat, Wien, Austria, 2001.

${ }^{13}$ F. Hu et al., J. Appl. Phys.109, 113906 (2011).

${ }^{14}$ X. L. Wang, E. Takayama-Muromachi, S. X. Dou, and Z. X. Cheng, Appl. Phys. Lett. 91, 062501 (2007).

${ }^{15}$ J. E. Greedan and W. Gong, J. Alloys Comp. 180, 281 (1992). 